\title{
A validated, transitional and translational porcine model of hepatocellular carcinoma
}

\author{
Kyle M. Schachtschneider ${ }^{1,2,3}$, Regina M. Schwind ${ }^{3}$, Kwame A. Darfour-Oduro ${ }^{1}$, Arun \\ K. De ${ }^{1}$, Lauretta A. Rund ${ }^{1}$, Kuldeep Singh ${ }^{4}$, Daniel R. Principe ${ }^{5}$, Grace Guzman ${ }^{6}$, \\ Charles E. Ray Jr. ${ }^{3,7}$, Howard Ozer7, Ron C. Gaba ${ }^{3}$ and Lawrence B. Schook ${ }^{1,3}$ \\ ${ }^{1}$ Department of Animal Sciences, University of Illinois, Urbana, IL, USA \\ ${ }^{2}$ Animal Breeding and Genomics Centre, Wageningen University, Wageningen, The Netherlands \\ ${ }^{3}$ Department of Radiology, University of Illinois at Chicago, Chicago, IL, USA \\ ${ }^{4}$ Veterinary Diagnostic Laboratory, University of Illinois, Urbana, IL, USA \\ ${ }^{5}$ College of Medicine, University of Illinois at Chicago, Chicago, IL, USA \\ ${ }^{6}$ Department of Pathology, University of Illinois at Chicago, Chicago, IL, USA \\ ${ }^{7}$ Department of Medicine, Division of Hematology/Oncology, University of Illinois at Chicago, Chicago, IL, USA \\ Correspondence to: Lawrence B. Schook, email: schook@illinois.edu \\ Keywords: hepatocellular carcinoma, human, porcine model, gene expression, interventional radiology \\ Received: October 21, $2016 \quad$ Accepted: June 05, $2017 \quad$ Published: June 29, 2017 \\ Copyright: Schachtschneider et al. This is an open-access article distributed under the terms of the Creative Commons Attribution \\ License 3.0 (CC BY 3.0), which permits unrestricted use, distribution, and reproduction in any medium, provided the original author \\ and source are credited.
}

\section{ABSTRACT}

Difficult questions are confronting clinicians attempting to improve hepatocellular carcinoma (HCC) outcomes. A large animal model with genetic, anatomical, and physiological similarities to humans is required to transition from mouse models to human clinical trials to address unmet clinical needs. To validate our previously reported inducible porcine cancer model (Oncopig) as a transitional HCC model, Oncopig hepatocyte cultures were transformed using Cre recombinase. The resulting porcine HCC cells (pHCC) expressed oncogenic TP5 $3^{\mathrm{R} 167 \mathrm{H}}$ and $K R A S^{\mathrm{G12D}}$, and displayed nuclear pleomorphisms with pale to granular cytoplasm arranged in expanded plates similar to human HCC histopathology. Human HCC transcriptional hallmarks were detected in pHCC cells using RNA-seq, including TERT reactivation, apoptosis evasion, angiogenesis activation, and Wnt signaling activation. Master regulators of gene expression were conserved across Oncopig and 18 human HCC cell lines. pHCC injection into SCID mice resulted in tumors recapitulating human HCC characteristics, including thick trabeculae formation, pseudoacini patterning, and sheets of wellvascularized stroma. Finally, autologous injection of pHCC cells subcutaneously yielded a tumor histologically characterized as Edmondson Steiner (HCC nuclear grade assessment system) grade 2 HCC with trabecular patterning and T-lymphocyte infiltration. These data demonstrate the Oncopig HCC model's utility for improving detection, treatment, and biomarker discovery relevant to human HCC.

\section{INTRODUCTION}

The overall 5-year survival rate of hepatocellular carcinoma (HCC) is $17.5 \%$ with more than half of cases diagnosed with regionally advanced disease, distant metastases, or unknown stages that carry relative survival rates of $10.9 \%, 3.1 \%$, and $6.1 \%$ according to the National Cancer Institute Surveillance, Epidemiology, and End Results Program (NCI SEER) stat fact sheets, respectively (https://seer.cancer.gov/statfacts/html/livibd.html; accessed 2017). Unfortunately, due to tumor characteristics, underlying liver disease and patient comorbidities, the vast 
majority of HCC patients are not candidates for surgery with curative intent, leaving at least $85 \%$ of patients to consider alternative palliative therapies [1]. Sorafenib is currently the only FDA approved targeted systemic therapy for advanced HCC and provides, on average, only 12 weeks of additional survival benefit with no difference in the median time to symptomatic progression [2]. Thus, there is an urgent need for novel and more effective treatment strategies. Treatment of HCC is complex, and there is limited high-level evidence for comparative evaluation of the many different non-surgical management approaches. This is further complicated by new technologies and locoregional therapies (LRTs) that are continually evolving. There are several medical specialists involved in the diagnosis and treatment of HCC, and treatment strategies are often dictated by the specialty of the consulting physician, rather than evidencebased consensus [3]. The critical need for an optimal HCC treatment strategy is demonstrated by previous clinical trials and the more than 1,000 related ongoing trials (https://www. clinicaltrials.gov/; accessed 2017).

The Oncopig cancer model (OCM) is a transgenic pig with Cre recombinase inducible porcine transgenes encoding $K R A S^{\mathrm{G} 12 \mathrm{D}}$ and $T P 53^{\mathrm{R} 167 \mathrm{H}}$, a commonly mutated signal transducing oncogene and tumor suppressor found in over $50 \%$ of human cancers, respectively [4]. Expression of these transgenes following exposure to adenovirus encoding Cre (AdCre) results in cell transformation leading to development of site, cell, and temporally specific tumors [4]. The OCM is of ideal size since it allows for utilization of the same tools that are used in human clinical practice. The size of the pig and its similarity to humans in anatomy, physiology, immunogenetics, and epigenetics [5] make it an ideal platform to develop an animal model that recapitulates human HCC and associated co-morbidities, e.g., obesity, cirrhosis, and nonalcoholic steatohepatitis (NASH). Pigs also require multiple genetic changes to develop cancer, and human mutations introduced into pig genes recapitulate molecular pathways associated with human cancers $[4,6]$. Furthermore, there is increasing evidence that intra-arterial therapies can stimulate cytokine production that may, in fact, drive tumor progression [7, 8]; thus, evaluating the role of concurrent targeted and systemic therapies is essential. The OCM can support studies aiming to satisfy various endpoints, including: overall survival, progression free survival, and costeffectiveness.

Changes in cytological features, the production of specific proteins, and alterations in gene expression and pathway regulation characterize human HCC. Transcriptional hallmarks of HCC include limitless replicative potential resulting from reactivation of TERT, evasion of apoptosis, and activation of VEGFA, PDGFA, or $A N G P T 2$, resulting in neoangiogenesis. Disturbances in cell cycle regulation due to $R B 1$ silencing or TP53 mutations, as well as activation of the Wnt signaling pathway are also commonly observed in human HCC $[9,10]$. The goal of this study was to validate the OCM as a model for human HCC in terms of phenotype, gene expression, and tumor development. Importantly, these factors are not yet considered when planning HCC therapy, however, we envision the OCM as a pivotal tool for defining this space. We hypothesized that the OCM mimics human HCC at the histologic and molecular level, providing an ideal transitional and translational research platform for improving detection, treatment, biomarker discovery, and other unmet clinical needs for HCC.

\section{RESULTS}

\section{Oncopig hepatocyte cultures recapitulate characteristics of human hepatocyte cultures}

Oncopig primary hepatocyte $(\mathrm{pPH})$ cell lines from three Oncopigs were cultured and transformed ( $\mathrm{pHCC}$ ) by exposure to AdCre in vitro, resulting in expression of mutant KRAS $S^{\mathrm{G} 12 \mathrm{D}}$ and TP53 $3^{\mathrm{R} 167 \mathrm{H}}$ transgenes in $\mathrm{pHCC}$ but not pPH cells (Figure 1A). The pPH cell lines displayed expression of important drug metabolic enzymes, regulatory genes, and hepatocyte functional genes that reduced over time in culture (Figure 1B), consistent with reports in human primary hepatocytes [11]. Also consistent with previous human HCC cell line studies [11], pHCC cells cultured with DMSO expressed similar levels of the same drug metabolism and hepatocyte functional genes as pPH cells (Figure 1C). In addition, Hep Par-1 positive staining (hepatocyte marker; $>90 \%$ ) was observed in all three pHCC cell lines (Figure 1D). Finally, while the number of apoptotic pPH cells rose from $6.45 \%$ on day 1 to $44.23 \%$ on day 15 of culture (Figure 1E), pHCC cells were still viable after 130 passages. Together, these results confirm the identity of the $\mathrm{pPH}$ and $\mathrm{pHCC}$ cells as primary and transformed hepatocytes, respectively.

\section{Oncopig pHCC cells recapitulate human HCC characteristics}

Cytopathological features of human HCC cells include round to polygonal and eosinophilic or granular cytoplasm with round to oval nuclei and prominent nucleoli [12]. pPH cells displayed bright and translucent cytoplasm with well-contrasted borders (Figure 2A). In contrast, blind assessment by a board-certified human pathologist with subspecialty training in Liver and Transplantation Pathology revealed pHCC cells displayed cytopathological characteristics similar to human HCC cells, including nuclear hyperchromatism pleomorphism, increased nuclear cytoplasmic ratio, and round to oval pale eosinophilic or granular cytoplasm (Figure 2B). Immunohistochemistry was utilized to determine whether pHCC cells underwent an epithelial-mesenchymal transition (EMT), a common tumor progression signal 

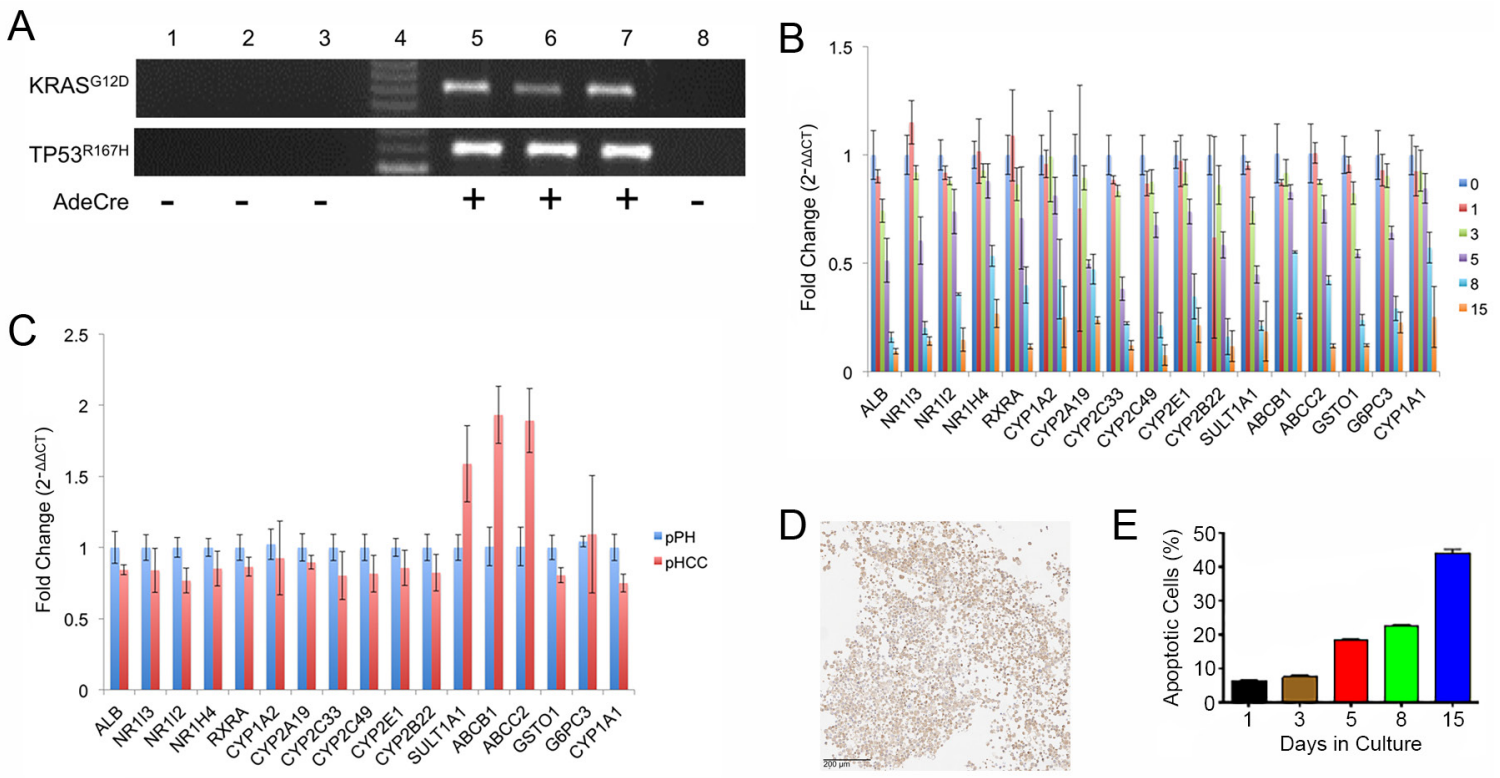

Figure 1: Hepatocyte gene expression and survival in culture. (A) Agarose gel electrophoresis of RT-PCR products for transgenes $\left(T P 53^{\mathrm{R} 167 \mathrm{H}}\right.$ and $\left.K R A S^{\mathrm{G} 12 \mathrm{D}}\right)$. Lane 1, pPH1 cell line; Lane 2, pPH2 cell line; Lane 3, pPH3 cell line; Lane 4, Molecular weight markers; Lane 5, pHCC1 cell line; Lane 6, pHCC2 cell line; Lane 7, pHCC3 cell line; Lane 8, Oncopig fibroblasts (negative control). (B) Expression of drug metabolism enzyme, nuclear receptor, and hepatocyte functional genes in pPH cells over time as assessed by qPCR. Numbers represent days in culture. (C) Relative expression of pHCC cells (passage 8) cultured in the presence of DMSO compared to pPH cells after 1 day of culturing as assessed by qPCR. (D) Positive Hep Par-1 staining of cultured pHCC cells (scale bar $200 \mu \mathrm{m}$ ). (E) Proportion of pPH cells positive for Annexin-V staining (apoptotic) detected by Flow Cytometry. Bar graphs indicate the average across the cell lines, with error bars representing the standard deviation.
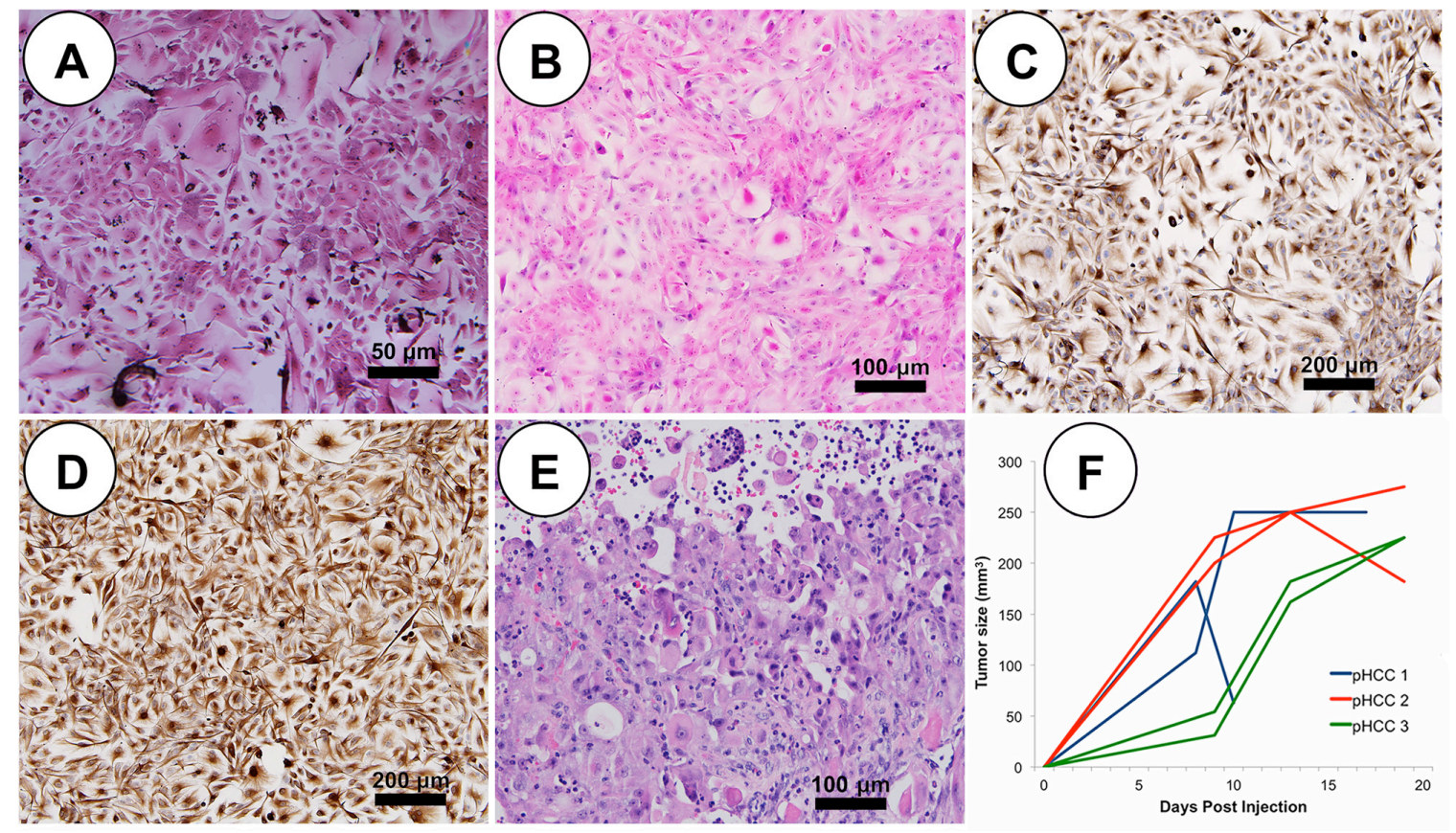

Figure 2: pHCC recapitulates cytologic and histologic features of human HCC both in vitro and in vivo. (A) Representative pPH cells in culture show polygonal shape with granular cytoplasm (scale bar $50 \mu \mathrm{m}$ ). (B) In culture, pleomorphic elongated pHCC have clear to granular cytoplasm and round to oval pleomorphic nuclei (scale bar $50 \mu \mathrm{m}$ ). (C) Positive cytokeratin immunostaining of cultured pHCC cells (scale bar $50 \mu \mathrm{m}$ ). (D) Positive vimentin immunostaining of cultured pHCC cells (scale bar $50 \mu \mathrm{m}$ ). (E) H\&E stained SC xenografted tumor (scale bar $50 \mu \mathrm{m}$ ). (F) Growth curve of SC xenografted tumors indicative of linear growth kinetics. 
observed in human HCC. While both pPH and pHCC cells expressed cytokeratin (epithelial marker; Figure $2 \mathrm{C}$ ), on average $80 \%$ of pHCC cells expressed vimentin (mesenchymal marker; Figure 2D), confirming pHCC cells have undergone an EMT. The pHCC cells also secreted alpha-fetoprotein (AFP; 40 to $50 \mathrm{ng} / \mathrm{ml}$ ), a serum marker observed in $60-70 \%$ of human HCC, whereas pPH cell supernatants contained no measurable amount of AFP after 48 hours (detection limit $3.12 \mathrm{ng} / \mathrm{ml}$ ), further demonstrating recapitulation of core cytological features of human HCC.

\section{Oncopig HCC tumor phenotype}

Each Oncopig pHCC cell line was injected subcutaneously (SC) and into the hepatic parenchyma of severe combined immunodeficiency (SCID) mice developing tumors within 21 days. SC tumors were histomorphologically characterized by expansive and infiltrative neoplastic cells with classical histologic features of human HCC [9], including arrangement of neoplastic cells in more than 3 cell layer thick trabeculae with regional pseudoacinar and sheet formations supported by a thick wall of vascularized stroma (Figure 2E). Consistent with previous in vivo tumor growth characterization studies [13], pHCC SC xenografted tumors exhibited a linear growth curve $\left(\mathrm{R}^{2}=0.688, \mathrm{p}<0.00001\right.$; Figure $2 \mathrm{~F}$ and Supplementary Figure 1). pHCC intrahepatic xenografted tumors were also histomorphologically characterized by classical histological features of human HCC, including arrangement of neoplastic cells in more than 3 cell layer thick expanded liver cell plates with regional pseudoacinar and sheet formations supported by a thick wall of vascularized stroma (Figure 3A), as well as expression of cytokeratin (Figure 3B) and vimentin (Figure 3C) consistent with the EMT observed in human HCC. Moreover, intrahepatic xenografted tumors displayed significant angiogenesis similar to human HCC (Figure 3D).

Autologous transplantation (SC) of pHCC cells induced a palpable mass in a single Oncopig, detected at 4 days post injection at the middle and high dose injection sites, and 19 days post injection at the low dose site. The diameter of the high dose mass reached $3 \mathrm{~cm}$ by day 14 (Figure 4A). The $2.7 \mathrm{~cm}$ mass was recovered at euthanasia (46 days post injection; Figure 4B) and blindly described histologically as Edmondson Steiner grade 2 human HCC with trabecular patterning (Figure 4C-4E). Masses at the middle and low dose sites were no longer palpable by 27
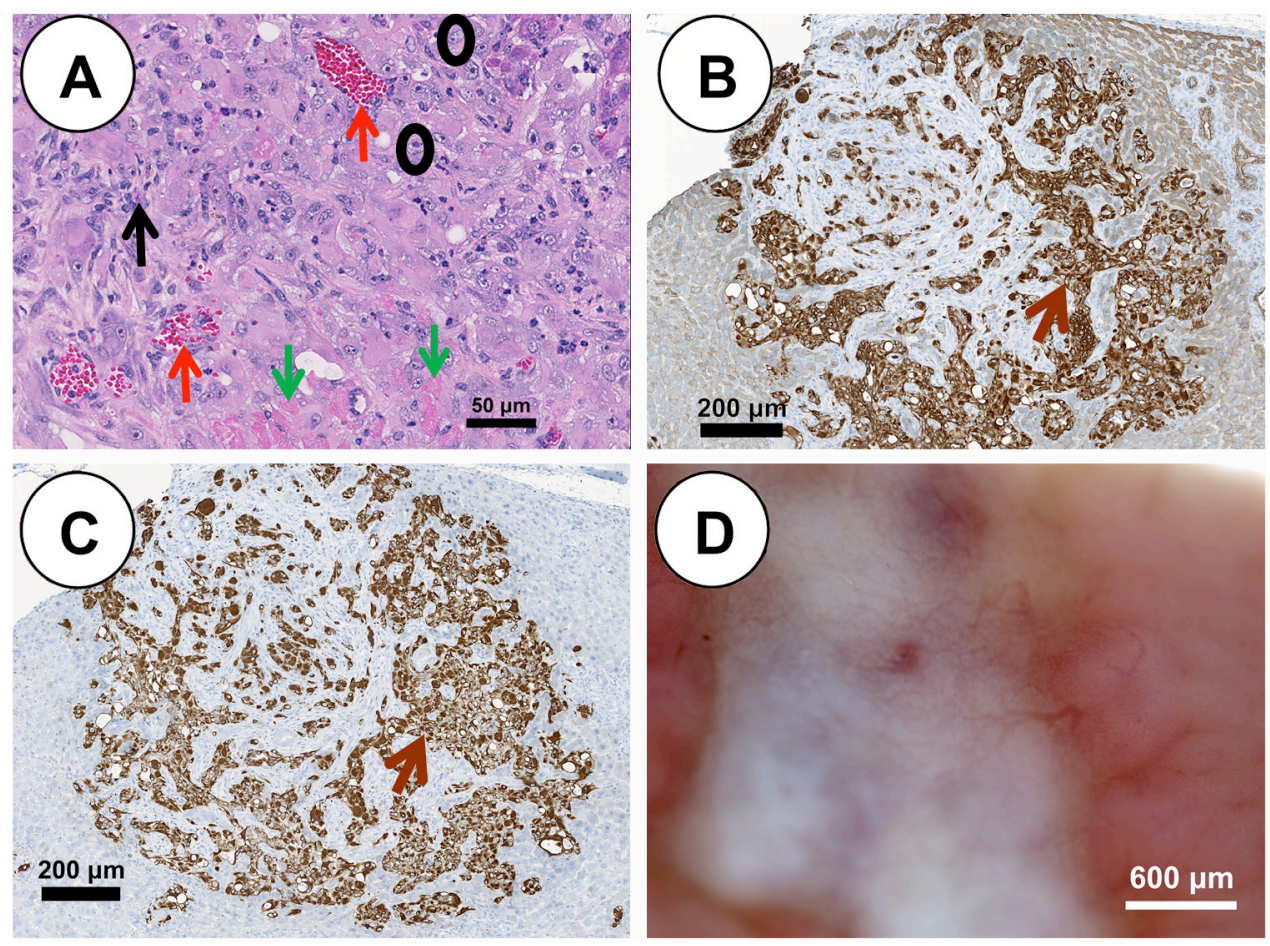

Figure 3: pHCC intrahepatic xenografted tumors recapitulate cytologic and histologic features of human HCC. (A) H\&E stained pHCC intrahepatic xenografted tumor reveals human HCC characteristics including blood vessels (red arrows), stroma (black arrow), neoplastic cells (black circles) and necrotic cells (green arrows) at 21 days post injection (scale bar $50 \mu \mathrm{m}$ ). (B) Positive cytokeratin immunostaining (brown arrow) of pHCC intrahepatic xenografted tumor (scale bar $200 \mu \mathrm{m}$ ). (C) Positive vimentin immunostaining (brown arrow) of pHCC intrahepatic xenografted tumor (scale bar $200 \mu \mathrm{m}$ ). (D) Blood vessel development in pHCC intrahepatic xenografted tumor (scale bar $600 \mu \mathrm{m}$ ). 
days post injection. Furthermore, diffuse T-lymphocyte infiltration into the autologous tumor was detected by immunohistochemistry (Figure 4F and 4G).

\section{Oncopig HCC gene expression profiles}

Transcriptional hallmarks of human HCC include: 1) disturbances in cell cycle regulation as a result of $R B I$ silencing or TP53 mutations; 2) sustained angiogenesis resulting from overexpression of VEGFA, PDGFA, or ANGPT2; 3) evasion of apoptosis; and 4) reactivation of TERT [10]. These transcriptional features were assessed in $\mathrm{pPH}$ and $\mathrm{pHCC}$ cell line gene expression profiles via RNA-seq. A total of 3,481 differentially expressed genes (DEGs) were identified between the $\mathrm{pHCC}$ and $\mathrm{pPH}$ cells, with 1,792 and 1,689 genes displaying elevated and reduced expression in the pHCC cells, respectively (Supplementary Tables 1 and 2). As expected, increased TP53 and KRAS expression was observed in pHCC cells (Supplementary Table 1), with the majority of transcripts originating from the mutant transgenes (ratio of mutant:WT reads of 17.55:1 and 3.40:1 for $T P 53$ and $K R A S$, respectively). In addition, expression profiles were more highly correlated within groups (Pearson's $r=0.97-0.98, p<0.0001$ ) than across groups (Pearson's $r=0.84-0.89, p<0.0001$; Supplementary Figure 2). Samples clustered by group when comparing the relative expression of all DEGs (Figure 5A), demonstrating the reproducible effect of mutant transgene expression on gene expression profiles.

\section{Activation of TP53 dependent cell cycle progression}

Uncontrolled proliferation through altered cell cycle regulation as a result of $R B 1$ silencing or TP53 mutation represents a key transcriptional feature of human HCC [10]. Gene ontology (GO) terms involved in regulation of cell growth and proliferation were enriched for DEGs in the pHCC cells (Figure 5B). The combined enrichment of these terms and mutant TP5 $3^{R 167 H}$ expression led to the hypothesis that TP53 dependent upregulation of cyclin D and B, factors promoting G1-to-S and G2-to-M transitions, led to increased cell cycle progression. As expected, reduced expression of cyclin D inhibitors $S F N$ and GADD45G was observed (Supplementary Table 2), resulting in increased expression of cyclin D genes CCND1 and CCND2 (Supplementary Table 1). In addition, increased expression of $C C N B 3$ was also observed (Supplementary Table 1). RBI silencing was not observed in the pHCC cells, suggesting activation of mutant TP5 $3^{R 167 H}$ is the main driver of cell cycle progression in $\mathrm{pHCC}$ cells.

\section{Expression of pro-angiogenic factors}

Increased angiogenesis is essential for tumors to receive nutrients, and hypervasularity resulting from overexpression of VEGFA, PDGFA, or ANGPT2 is a key hallmark of human $\mathrm{HCC}[14,15]$. ANGPT2 primes the vasculature for angiogenic response in the presence of VEGFA [16], which induces angiogenesis [17] and is upregulated by PDGFA [18]. Consistent with the observed hypervascularity of intrahepatic pHCC tumors (Figure 3D), GO terms involved in regulation of angiogenesis were enriched for DEGs in pHCC cells (Figure 5C). In addition, elevated expression of PDGFA and ANGPT2 was observed (Supplementary Table 1), as well as elevated and reduced expression of a number of pro- and antiangiogenic factors, respectively (Figure 5D).

\section{Evasion of apoptosis}

Altered regulation of genes involved in apoptosis results in evasion of apoptosis in cancer cells, and was observed in the pHCC cells through enrichment of GO terms involved in the regulation of apoptosis (Figure 6A). A number of anti-apoptotic factors in these pathways were highly expressed (Figure 6B), including TWIST1 (Supplementary Table 1), which protects cells from oncogene-induced apoptosis [19] and is overexpressed in human HCC [20]. In addition, many pro-apoptotic factors were lowly expressed (Figure 6B), including those expressed at low levels in human HCC, such as TNFSF10, which induces apoptosis in cancer but not normal cells [21], and STAT1, which mediates the growth inhibition and apoptotic activities of IFN- $\gamma$ [22]. ATF5 induces apoptosis in response to the chemotherapy drug cisplatin [23] and was also lowly expressed in pHCC cells (Supplementary Table 2).

\section{Activation of telomere maintenance}

The TERT gene encodes for telomerase, an RNA polymerase that adds telomere repeat sequences at the end of chromosomes. As in humans, the porcine TERT gene is silenced in somatic cells, resulting in telomere shortening over time [9], eventually resulting in cell death. TERT is expressed in cancer cells to achieve limitless replicative potential [24], and increased TERT expression is observed in $90 \%$ of human HCC [25]. Consistent with human HCC, elevated TERT expression was observed in $\mathrm{pHCC}$ cells (Supplementary Table 1), indicating activation of telomere maintenance.

\section{Subclass specific Wnt signaling activation}

Activation of Wnt signaling promotes increased HCC cell proliferation, migration, and invasion [26] through binding of Wnt ligands to frizzled receptors, resulting in translocation of $\beta$-catenin into the nucleus. Wnt ligand and frizzled receptor overexpression indicates aberrant Wnt signaling activation and is detected in over half of HCC cases [27-30]. Increased expression of Wnt ligands $W N T 2 B, W N T 9 A$, and $W N T 10 B$ was observed in 
pHCC cells (Supplementary Table 1). Elevated expression of the frizzled receptors FZD6 and FZD7, as well as the co-receptor LRP6 was also observed (Supplementary Table 1). In addition, HCC tumors can be classified based on Wnt related gene expression [31]. The Wnt/TGF $\beta$ subclass is characterized by an aggressive phenotype and elevated expression of classical Wnt target genes, while the CTNNB1 subclass is characterized by a less aggressive phenotype and elevated expression of liver specific Wnt target genes. Elevated expression of 10 genes related to the Wnt/TGF $\beta$ subclass was observed in the pHCC cells, 8 of which are involved in Wnt pathway activation, compared
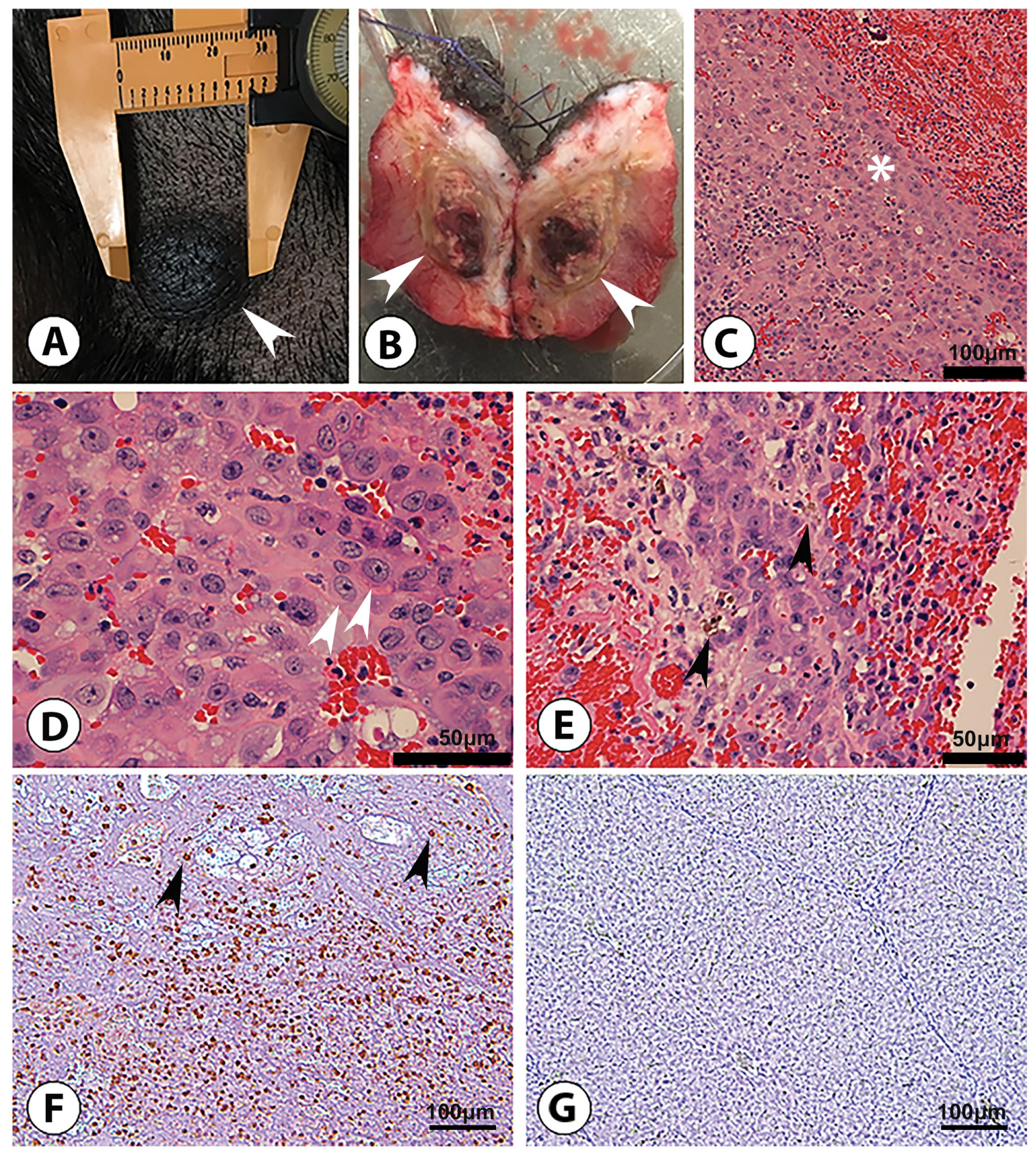

Figure 4: Subcutaneous HCC formation in an Oncopig following autologous transfer of pHCC cells. (A) $3 \mathrm{~cm}$ right flank nodule (arrowhead) after 14 days of tumor growth, at which point the nodule was excised. (B) Excised $2.7 \mathrm{~cm}$ nodule (46 days post injection) displays transected ovoid subcutaneous tumor (arrowheads). (C-E) H\&E examination shows malignant cells consistent with Edmondson-Steiner grade $2 \mathrm{HCC}$; these include a trabecular (ribbon-like) pattern of malignant cells (* in panel C; scale bar $100 \mu \mathrm{m}$ ), characterized by acidophilic and granular cytoplasm, ovoid to round hyperchromatic nuclei, and increased nuclear to cytoplasmic ratio (arrowheads in panel D; scale bar $50 \mu \mathrm{m}$ ) containing wispy brown material (arrowheads in panel E; scale bar $50 \mu \mathrm{m}$ ) representing bile typical of hepatocyte differentiation. (F) Anti-pig CD3 staining reveals diffuse CD3 T-lymphocyte (arrowheads) infiltration into tumor, indicating a "hot" tumor potentially susceptible to immunotherapy (scale bar $100 \mu \mathrm{m}$ ). (G) Anti-pig CD3 staining of control (non-tumorous) Oncopig liver tissue displays no CD3 T-lymphocyte presence (scale bar $100 \mu \mathrm{m}$ ). 
to 2 for the CTNNB1 subclass (Figure 6C). The CTNNB1 subclass is also characterized by increased expression of 9 liver-related Wnt target genes, 5 of which are annotated in the pig genome. Elevated expression of only one of these (EPHB2) was observed in pHCC cells, while 3 displayed reduced expression (Figure $6 \mathrm{C}$ ). Together, these results provide evidence of Wnt signaling activation in $\mathrm{pHCC}$ cells resembling the Wnt/TGF $\beta$ subclass of human HCC.

\section{Master regulators of Oncopig and human HCC cell line expression}

Master regulators are transcription factors (TFs) that play a key role in regulating gene expression. To determine whether the same TFs underlie genomewide expression changes in human and Oncopig HCC, transcriptional regulatory networks were reverseengineered from Oncopig and human HCC cell line gene expression profiles, resulting in the identification of TFs underlying altered expression of co-expressed genes. Master regulators of reduced gene expression were highly conserved, with 8 TFs (EP300, HNF4G, HDAC2, NR2F2, FOXA1, HNF4A, CEBPB, and FOXA2) identified in the Oncopig and all human HCC cell lines (Table 1). In addition, EP300 target genes were the most highly enriched in both the Oncopig and the majority of human (13/18) HCC cell lines. Although master regulators driving increased gene expression were identified in the Oncopig pHCC cells (Supplementary Table 3), the same TFs were not identified in the human HCC cell lines. Unlike the master regulators of reduced gene expression, none of the identified master regulators driving increased gene expression were shared across all 18 human HCC cell lines (Supplementary Table 4). No master regulator of increased gene expression was shared across more than 16 human HCC cell lines, highlighting the high level of variability in regulation of elevated compared to reduced gene expression in human HCC.
A

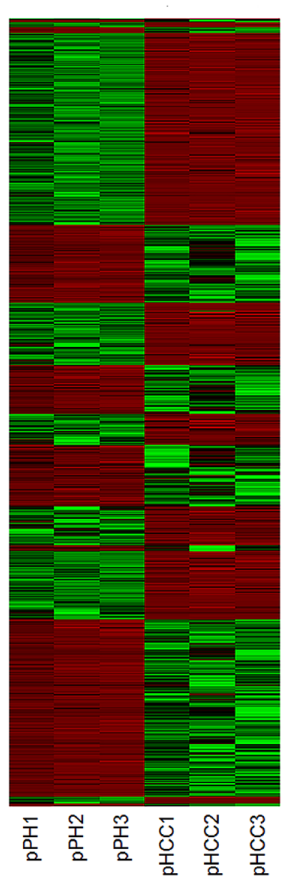

Color Key

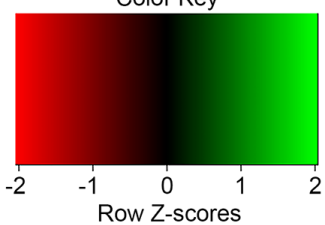

B

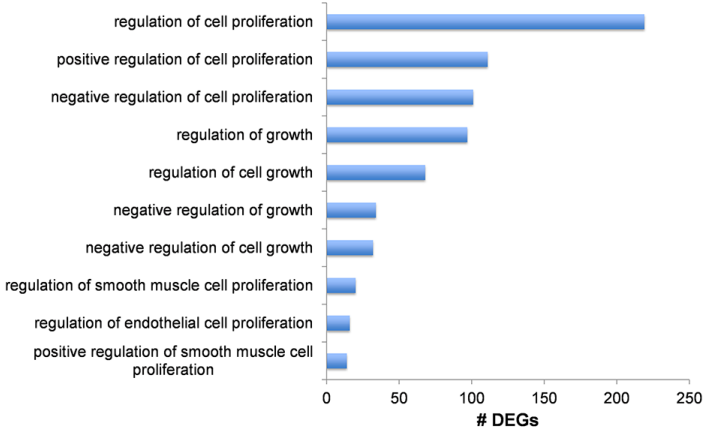

C

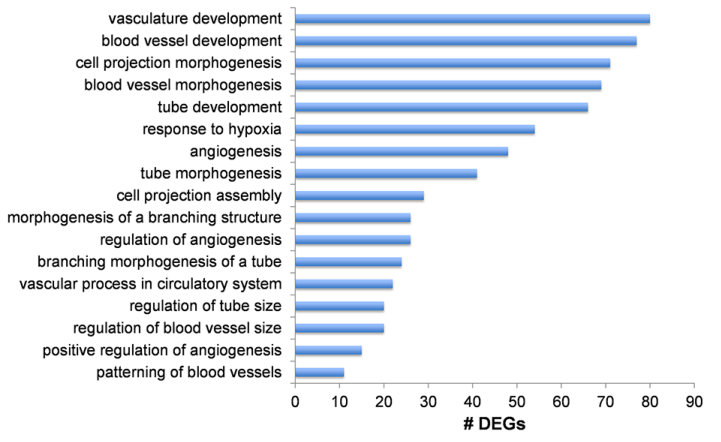

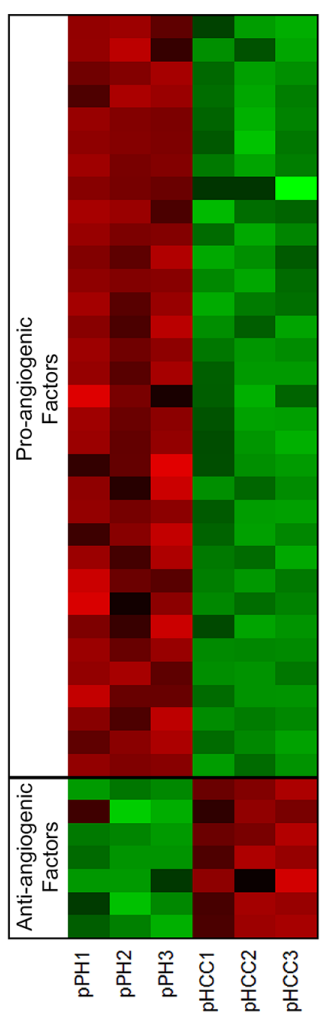

Figure 5: pHCC cell line expression related to cell cycle progression and angiogenesis. (A) Heat map of normalized expression levels of 3,481 differentially expressed genes (DEGs) for individual cell lines, represented as z-scores. (B) Enriched gene ontology (GO) terms associated with regulation of cell growth and proliferation. (C) Enriched GO terms associated with regulation of angiogenesis. (D) Heatmap of pro- and anti-angiogenic factors displaying elevated and reduced expression in pHCC cell lines, respectively, represented as z-scores. 


\section{Independent validation of RNA-seq results}

To validate the RNA-seq expression results, genes displaying elevated and reduced expression were randomly chosen for expression analysis using qPCR. The directional change in expression for each gene was consistent between RNA-seq and qPCR (Supplementary Table 5). In addition, a strong correlation (Pearson's $r=0.994, p$ value $<0.0001$ ) was observed between the $\log 2$ fold change differences obtained using RNA-seq and qPCR, demonstrating the reliability of the reported RNA-seq results.

\section{Cirrhosis induction}

As $\mathrm{HCC}$ often develops in patients presenting with $\mathrm{HCC}$ risk factors such as cirrhosis, an ideal HCC model must also be able to reflect comorbidities associated with HCC development. In order to demonstrate the ability of the OCM to model relevant comorbidities, cirrhosis induction was performed on 2 Oncopigs via transarterial alcohol injection. This procedure resulted in histologic changes-including irregular and morphologically distorted hepatic lobules circumferentially surrounded by thick fibrous septa - consistent with stage 4 liver fibrosis (cirrhosis) within 8 weeks (Figure 7).

\section{DISCUSSION}

There are a number of difficult questions confronting clinicians and clinical investigators attempting to improve HCC outcomes. The existence of numerous competing phase II and phase III clinical trials impairs accrual to all trials because of limited patient availability. Prioritization of trials with substantial scientific rationale for advancing new therapeutic agents or procedures for HCC through the clinical pipeline, from phase I through III has become critical. Clearly a relevant, biologically analogous animal HCC model would accelerate therapeutic discovery while offering a more efficient, cost effective mechanism for therapeutic evaluation of this deadly disease.

The OCM was designed and developed to provide a large animal transitional, translational, and transformative model for accelerating clinical trials and supporting noninvasive image-guided procedures, radiation oncology, drug metabolism, immune therapy of cancer, surgical training, and technology development (e.g., early detection and screening) [32-37]. The large size of the pig and its similarity in anatomy, physiology, metabolism, genetics, and epigenetics to humans make it an ideal research and development platform. The OCM carries a Cre recombinase inducible porcine $K R A S^{G 12 D}$ and
A
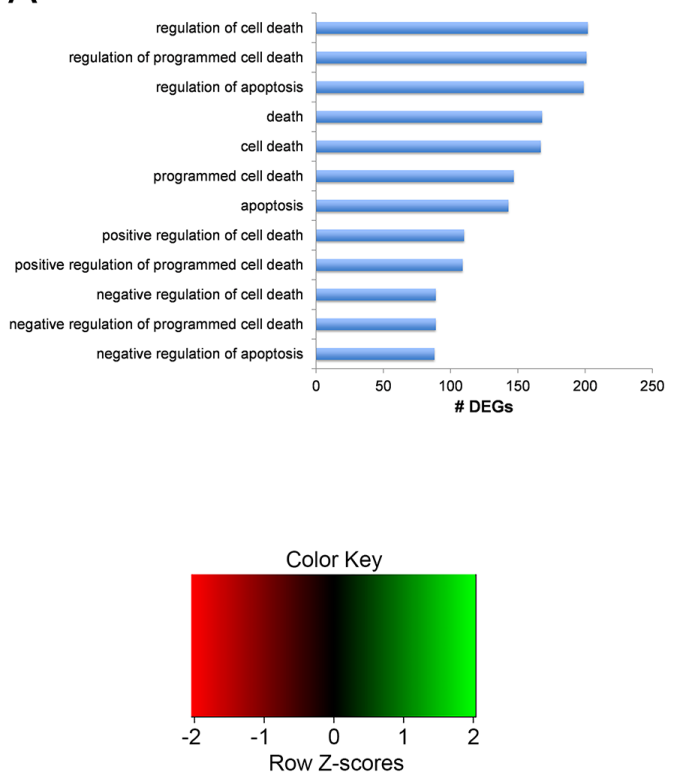

B

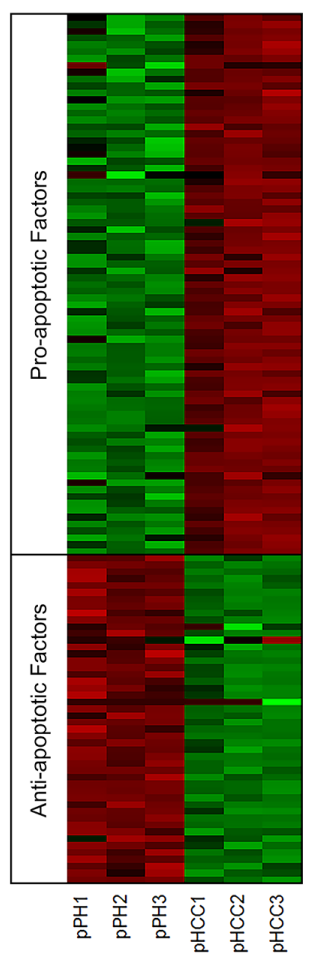

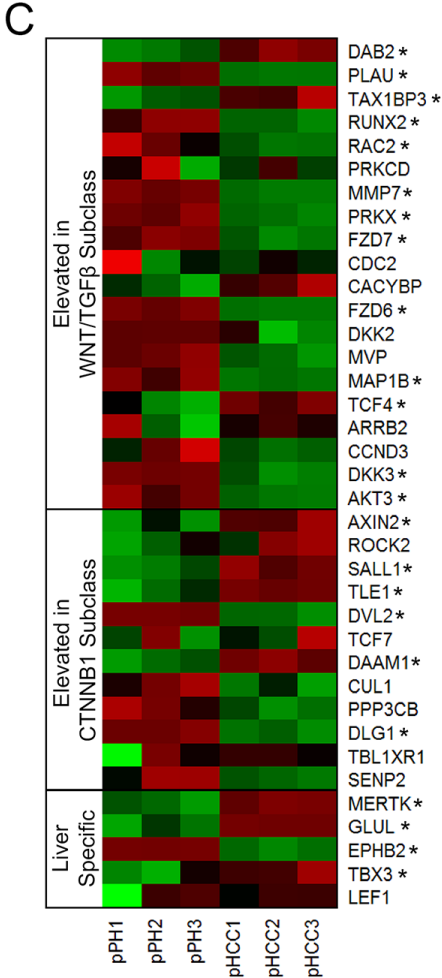

Figure 6: Gene expression related to apoptosis and Wnt signaling in pHCC cell lines. (A) Gene ontology (GO) terms enriched for differentially expressed genes (DEGs) associated with regulation of apoptosis. (B) Heatmap of pro- and anti-apoptotic factors displaying reduced and elevated expression in $\mathrm{pHCC}$ cell lines, respectively, represented as z-scores. (C) Expression profiles of genes whose elevated expression is used to classify human HCC, indicating pHCC cell lines represent the WNT/TGF $\beta$ subclass, represented as z-scores. * denotes $\mathrm{q}<0.05$. 
Table 1: Master regulators of genes with reduced expression in Oncopig and human HCC cell lines

\begin{tabular}{|c|c|c|c|c|c|c|c|c|c|c|c|c|c|c|c|c|c|c|c|}
\hline $\begin{array}{l}\text { Transcription } \\
\text { factors }\end{array}$ & $\begin{array}{l}\text { Oncopig } \\
\text { pHCC }\end{array}$ & 7703 & Focus & Нер3В & $\begin{array}{c}\text { Hep3B- } \\
\text { TR }\end{array}$ & Нер40 & HepG2 & HLE & HLF & HUH-1 & HUH-6 & HUH-7 & $\begin{array}{l}\text { SK- } \\
\text { Hep1 }\end{array}$ & $\begin{array}{c}\text { SNU- } \\
182\end{array}$ & $\begin{array}{l}\text { SNU- } \\
387\end{array}$ & $\begin{array}{c}\text { SNU- } \\
389\end{array}$ & $\begin{array}{c}\text { SNU- } \\
449\end{array}$ & $\begin{array}{c}\text { SNU- } \\
475\end{array}$ & PLC/PRF/5 \\
\hline STATI & 769 & - & - & - & - & - & - & - & - & - & - & - & - & - & - & - & - & - & - \\
\hline EP300 & 607 & 431 & 456 & 450 & 438 & 596 & 307 & 545 & 392 & 343 & 379 & 385 & 488 & 270 & 462 & 664 & 652 & 626 & 410 \\
\hline FOXA2 & 541 & 384 & 418 & 394 & 396 & 553 & 298 & 477 & 362 & 312 & 349 & 218 & 451 & 245 & 431 & 638 & 577 & 561 & 386 \\
\hline SPII & 535 & - & - & - & - & - & - & - & - & - & - & - & - & - & - & - & - & - & - \\
\hline FOXAl & 532 & 448 & 478 & 441 & 452 & 630 & 324 & 559 & 408 & 368 & 398 & 382 & 506 & 286 & 506 & 712 & 657 & 667 & 449 \\
\hline$H N F 4 A$ & 522 & 435 & 463 & 421 & 429 & 556 & 304 & 542 & 383 & 347 & 387 & 370 & 477 & 285 & 436 & 672 & 654 & 644 & 408 \\
\hline$H N F 4 G$ & 391 & 408 & 424 & 421 & 378 & 550 & 293 & 500 & 364 & 331 & 351 & 382 & 458 & 248 & 445 & 628 & 597 & 584 & 390 \\
\hline CEBPB & 337 & 372 & 384 & 380 & 276 & 357 & 33 & 442 & 339 & 221 & 235 & 252 & 419 & 244 & 408 & 553 & 527 & 535 & 366 \\
\hline HNFIA & 274 & - & - & - & - & - & 167 & - & 330 & - & - & - & - & - & - & - & - & - & - \\
\hline NFIC & 234 & 215 & 226 & 122 & 179 & 169 & - & 257 & 208 & 173 & 114 & 172 & 243 & 128 & 228 & 186 & 179 & 291 & 205 \\
\hline$H D A C 2$ & 223 & 353 & 396 & 369 & 206 & 498 & 120 & 451 & 320 & 157 & 147 & 161 & 396 & 236 & 387 & 497 & 442 & 489 & 346 \\
\hline$N R 2 F 2$ & 174 & 152 & 149 & 137 & 141 & 183 & 95 & 179 & 141 & 123 & 129 & 124 & 170 & 80 & 153 & 218 & 204 & 198 & 148 \\
\hline $\mathrm{NR} 3 \mathrm{Cl}$ & 156 & - & - & 91 & - & - & - & - & - & - & - & 157 & - & - & - & - & - & - & - \\
\hline FOXA3 & 115 & - & - & - & - & - & - & - & - & - & - & - & - & - & - & - & - & - & - \\
\hline GATA3 & 102 & - & - & - & - & - & 69 & - & - & - & - & - & - & - & - & - & - & - & - \\
\hline$E 2 F 1$ & 77 & - & - & - & - & - & - & - & - & - & - & - & - & - & - & - & - & - & - \\
\hline STAT2 & 41 & - & - & - & - & - & 41 & - & - & - & - & - & - & - & - & - & - & - & - \\
\hline
\end{tabular}

The number of target genes with reduced expression for each transcription factor is indicated for each cell line. (-) Indicates that transcription factor target genes were not enriched (i.e. overrepresented) in the list of genes with reduced expression for a given cell line.

$T P 53^{R 167 H}$ construct, a commonly mutated oncogene and tumor suppressor gene in human cancers, respectively. This study validates the hypothesis that genetic alteration of molecular pathways in the pig, commonly disrupted in human cancers, provides a standardized histologic tumor model analogous to human tumors to support new investigations of therapeutic interventions.

The ability to induce cirrhosis in the OCM provides the opportunity to assess the role of cirrhosis in tumorigenesis through development of $\mathrm{pHCC}$ lines from normal and cirrhotic livers. In addition, because patients with vascular invasion and cirrhosis carry an $83 \%$ likelihood of recurrence, versus $12 \%$ of patients presenting without vascular invasion and cirrhosis [38], the OCM provides a unique opportunity to stage $\mathrm{HCC}$ with and without cirrhosis to define mono- or combination therapeutic approaches in a more controlled way than can be done in human patients. However, although cirrhosis was successfully modeled in the OCM, intra-hepatic tumors were not developed herein. This limitation requires that further studies be undertaken to produce orthotopic tumors via engraftment of SC HCC tumors into the liver before this level of modeling can be achieved. Finally, while autochthonous HCC tumors have been developed in a previously described chemically induced porcine HCC model $[39,40]$, this model takes over 1 year to develop clinically relevant tumors and
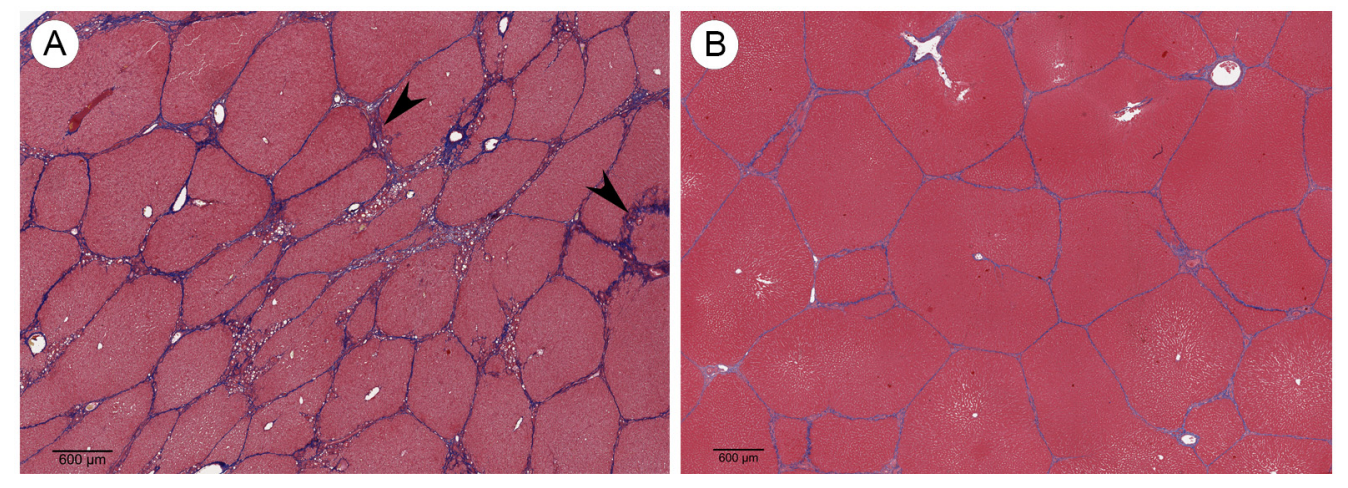

Figure 7: Cirrhosis induction. (A) Trichrome stained Oncopig liver 8 weeks following cirrhosis induction shows irregular and morphologically effaced hepatic lobules circumferentially surrounded by thick fibrous septa (arrowheads) consistent with stage 4 liver fibrosis (cirrhosis; scale bar $600 \mu \mathrm{m}$ ). (B) Trichrome stain of normal Oncopig control liver shows morphologically non-expanded portal tracts maintaining their usual hexagonal distribution, without cetrilobular venular and sinusoidal thickening (scale bar $600 \mu \mathrm{m})$. 
does not allow for control of tumor number, location, or comorbidities, rendering it potentially less suitable for preclinical and co-clinical trials.

The results presented here demonstrate the Oncopig HCC model recapitulates core cytological phenotypic characteristics of human HCC, resembles poorly differentiated human HCC with cellular pleomorphy, and affords an opportunity to utilize an animal model that recapitulates human $\mathrm{HCC}$ presenting with poor prognosis. Critical to the utilization of animal models in studying human diseases is the reproducibility of experiments. In this study, independently derived cell lines obtained from Oncopigs from 2 different litters demonstrated reproducible human HCC characteristics and gene expression profiles, providing evidence for the OCM as a robust, validated, and consistent model of human HCC. The pHCC cell lines also secrete AFP, regarded as the most useful serum protein biomarkers for HCC detection in humans [41]. In high- risk populations, intermittent AFP serum levels and liver ultrasounds are utilized as surveillance strategies, but as HCC is detected at a localized stage in fewer than $50 \%$ of cases, there remains a need for more reliable screenings (https:// www.cancer.gov/types/liver/patient/liver-screening-pdq; accessed 2017). The secretion of AFP by pHCC cells suggests that the Oncopig HCC model mimics AFPproducing $\mathrm{HCC}$, with the advantage that AFP levels can be used to monitor tumor progression and treatment response in the Oncopig in drug trials for later application to human HCC. In addition, since the OCM depends on the same cumulative genetic mutations and mimics key transcriptional hallmarks of human $\mathrm{HCC}$, there exists the potential for biomarker discovery using serum and liver samples at various reproducible stages of tumorigenesis.

Tumor development resulting from engraftment of Oncopig pHCC cells into mouse livers recapitulated phenotypic features of human HCC. This was also the case for tumors produced via autologous injection of Oncopig pHCC cells SC. Although xenografted tumors typically exhibit a Gompertz or exponential-linear growth curve [13], a linear growth curve was observed for the SC xenografted tumors described in this study. While surprising, it is likely that the exponential growth phase was missed in this study due to the relatively few number of tumor measurements taken (2-4/tumor over a 3 week period) compared to the number recommended for assessment of high growth rate tumors $(3 \mathrm{x} /$ week) [42]. It is unclear at this time whether the palpable masses at the middle and low dose autologous transfer sites represent tumors that regressed, or masses caused by an inflammatory response and subsequent clearing of the pHCC cells before a tumor mass could be established. In either case, the successful formation of an HCC tumor at the high dose site indicates that autologous tumor formation is feasible, and that additional studies are required to confirm reproducibility.
Of clinical relevance was the significant angiogenesis exhibited by the Oncopig HCC tumors as opposed to rodent models. Human HCC tumors are typically hypervascular [43], making them amenable to anti-angiogenic gene therapy. These results, in addition to the altered expression of genes involved in angiogenesis regulation, suggest the Oncopig HCC model is more suitable for testing LRTs and anti-angiogenic therapies than commonly used rodent models. However, it is important to note that while hypervascularization of Oncopig $\mathrm{HCC}$ tumors and elevated expression of proangiogeneic factors in $\mathrm{pHCC}$ cell lines was observed, orthotopically engrafted tumors may not mimic the vascularity of autochthonous tumors, which may influence the relevance of this model for locoregional therapy studies. Therefore, further studies are required to determine the hypervascularity of orthotopically engrafted Oncopig HCC tumors.

Immunotherapy trials utilizing immune checkpoint inhibitors have become a major focus of research for cancer treatment. In order for these treatments to be effective, tumors must demonstrate high levels of lymphocyte infiltration prior to treatment. These tumors presenting with significant lymphocyte infiltration are referred to as "hot" tumors. Tumor infiltrating T-lymphocytes were identified in the Oncopig HCC tumors presented here, indicating these are "hot" tumors potentially utilizable for immunotherapy trials. Although characterization of T-cell populations and tumor cell immunogenicity has been performed in other Oncopig tumor types (Overgaard N.H. et al, 2017 AACR Annual Meeting Abstract \#2587), future studies are required to further characterize the immune environment of Oncopig HCC tumors.

It was further demonstrated that $\mathrm{pHCC}$ cells closely parallel human HCC at the transcriptomic level in terms of TP53 dependent cell cycle regulation and CCND1 overexpression, increased angiogenesis through elevated PDGFA and ANGPT2 expression, evasion of apoptosis, reactivation of TERT allowing uncontrolled cellular replication, and Wnt signaling activation. Furthermore, Oncopig pHCC expression profiles most closely resemble the Wnt/TGF $\beta$ subclass of human HCC, a subclass characterized by an aggressive HCC clinical phenotype. Given the focus on identification of key pathways for the development of targeted human HCC treatments, the OCM provides a suitable model in which novel targeted therapies, such as those targeting the Wnt pathway, can be tested before transitioning to clinical trials.

A number of the master regulators of reduced gene expression identified across Oncopig and human HCC cell lines have been previously implicated in HCC development. $H D A C 2$ is a transcriptional repressor whose expression promotes cell cycle progression by down regulating genes involved in G1 cell cycle arrest in human HCC [44], while $H N F 4 A$ promotes cellular proliferation and loss of 
epithelial morphology when lowly expressed in human HCC [45]. In addition, FOXA2 overexpression inhibits migration and invasion in human HCC cell lines [46], while EP300 expression is associated with an aggressive HCC phenotype [47], highlighting the importance of these TFs in $\mathrm{HCC}$ patient prognosis. Given the previous implication of these master regulators in HCC development, the role of the other master regulators identified across Oncopig and human HCC cell lines (NR2F2, HNF4G, FOXA1 and $C E B P B)$ warrant further investigation. In conclusion, the identification of consistent pathway alterations and master regulators of genes displaying reduced expression across Oncopig and human $\mathrm{HCC}$ cell lines further validates the OCM as a model for human HCC.

Although master regulators of reduced gene expression were conserved across Oncopig and the 18 human HCC cell lines, master regulators of elevated gene expression were not. In addition to not being conserved across species, none of the master regulators driving increased gene expression were shared across all 18 human HCC cell lines. This result highlights the high level of variability in regulation of elevated compared to reduced gene expression in human HCC, and helps explain the lack of shared master regulators of elevated gene expression between Oncopig and human HCC cell lines. It is important to note that this study utilized expression profiles from $\mathrm{pHCC}$ cell lines, and although these profiles recapitulated many of the transcriptional hallmarks of human $\mathrm{HCC}$, further in vivo expression profiling is required to further confirm the similarities observed between Oncopig and human HCC cell lines.

In summary, we present data demonstrating the ability of Oncopig pHCC cell lines to recapitulate key features of human $\mathrm{HCC}$, providing validation for the use of the OCM for human HCC research. This model will enable the testing of different HCC treatment techniques and the evaluation of histologic, radiographic, and pathological responses in a model more similar to human HCC than currently available small animal models.

\section{MATERIALS AND METHODS}

\section{Animals}

All animal procedures were approved by The University of Illinois Institutional Animal Care and Use Committee (IACUC protocol number, 14125, 14126, and 15121). All Oncopigs were crossbred animals (Minnesota Minipig sire and Yorkshire dams) and heterozygous for the transgene. In total, 6 Oncopigs and 15 SCID mice were used in this study.

\section{pPH isolation and transgene activation}

pPH cells were isolated from 3 individual Oncopigs utilizing a modified Meng's method [48] to produce 3 individual pPH lines. A portion of a liver lobe was collected from each Oncopig, washed 2-3 times with ice cold phosphate buffer saline (PBS) and placed in ice cold Krebs Ringer Solution. Liver samples were cannulated into visible blood vessels on the cut surface and flushed with $500 \mathrm{ml}$ of buffer A $(8.3 \mathrm{~g} / \mathrm{l}$ $\mathrm{NaCl}, 0.5 \mathrm{~g} / 1 \mathrm{KCl}, 2.4 \mathrm{~g} / 1 \mathrm{HEPES}$, and $0.19 \mathrm{~g} / 1$ EGTA at $\mathrm{pH} 7.4$ ) at $37^{\circ} \mathrm{C}$, followed by perfusion of $500 \mathrm{ml}$ buffer $\mathrm{B}(8.3 \mathrm{~g} / 1 \mathrm{NaCl}, 0.5 \mathrm{~g} / 1 \mathrm{KCl}$, and $2.4 \mathrm{~g} / 1 \mathrm{HEPES})$ at $37^{\circ} \mathrm{C}$. Tissues were further perfused using a prewarmed $\left(37^{\circ} \mathrm{C}\right)$ digestion Buffer $\mathrm{C}(3.9 \mathrm{~g} / 1 \mathrm{NaCl}, 0.5$ $\mathrm{g} / 1 \mathrm{KCl}, 2.4 \mathrm{~g} / 1 \mathrm{HEPES}, 0.7 \mathrm{~g} / 1 \mathrm{CaCl} 2 \mathrm{X} 2 \mathrm{H} 2 \mathrm{O}$, and $0.1 \%$ Collagenase, type IV). Following digestion, the liver capsules were removed and dissolved cells were liberated by gently shaking the liver specimen in ice cold buffer D (9.91 g/l HBSS without calcium and magnesium, $2.4 \mathrm{~g} / 1 \mathrm{HEPES}$, and $2.0 \mathrm{~g} / 1$ bovine serum albumin). Regions that were not well perfused were cut with a scalpel to release additional hepatocytes. The resulting cell suspensions were subjected to serial filtering to decrease contamination of other cell types through size-specific exclusion. Cell suspensions were first filtered through a $100 \mu \mathrm{m}$ nylon mesh (BD Falcon, Franklin Lakes, NJ, USA) and centrifuged at $50 \mathrm{x} \mathrm{g}$ for $3 \mathrm{~min}$ at $4^{\circ} \mathrm{C}$. Thereafter, cells were incubated for $10 \mathrm{~min}$ with $\mathrm{DNase} 1$ containing buffer at $4^{\circ} \mathrm{C}$ to break down cell clumps and digest damaged cells. The resulting suspensions were filtered through a $70 \mu \mathrm{m}$ nylon mesh (BD Falcon, Franklin Lakes, NJ, USA) and centrifuged at $50 \mathrm{x}$ g for $3 \mathrm{~min}$. Cell pellets were washed three times with ice cold buffer D before resuspension. $2 \times 10^{6}$ cells were seeded in $5 \mathrm{ml}$ culture medium (William's E supplemented with $100 \mathrm{mU} / \mathrm{ml}$ penicillin, $100 \mu \mathrm{g} / \mathrm{ml}$ streptomycin, $2 \mathrm{mM}$ glutamate and $10 \%$ Fetal bovine serum) in T25 culture flasks. 4 to 6 hours following seeding culture medium and unattached cells were discarded and replaced with fresh medium. Medium was replaced every 24 hours for the duration of pPH culturing, and pPH cell lines were never passed.

\section{pPH cell transformation}

On day 2 of culture, the medium for each of the $\mathrm{pPH}$ cell lines was changed to low serum $(5 \% \mathrm{FBS})$ and Ad5CMVCre-eGFP (AdCre; University of Iowa Vector Core, Iowa City, IA, USA) was added at a 200 to $500 \mathrm{MOI}$ as previously described [4]. Following AdCre treatment, as the resulting $\mathrm{pHCC}$ cells reached confluency, the medium was removed and cells were detached by incubating with trypsin until the cells became detached following agitation of the flask. Cells were passed by plating at 1:2 dilution into new T25 culture flasks in $5 \mathrm{ml}$ culture medium. At passage 4 the pHCC medium was transitioned to DMEM supplemented with $100 \mathrm{mU} / \mathrm{ml}$ penicillin, $100 \mathrm{ug} / \mathrm{ml}$ streptomycin, $2 \mathrm{mM}$ glutamate and 10\% Fetal bovine serum. 


\section{DMSO treatment of the pHCC cells}

The pHCC cells were seeded at low density ( $2 \mathrm{X}$ $10^{4}$ cells $\left./ \mathrm{cm}^{2}\right)$ in supplemented William's E $(10 \%$ FBS, $100 \mathrm{mU} \cdot \mathrm{mL}^{-1}$ penicillin, $100 \mu \mathrm{g} \cdot \mathrm{mL}^{-1}$ streptomycin, $2 \mathrm{mM}$ glutamate). At confluence, the medium was supplemented with $2 \%$ DMSO. The medium was changed every 2-3 days. The cells were cultured in presence of DMSO for 8 passages before collecting for RT-PCR analysis.

\section{Apoptosis assay}

Flow cytometric quantification of $\mathrm{pPH}$ apoptosis was performed on day $1,3,5,8$, and 15 of culture. The FITC Annexin V/Dead Cell Apoptosis Kit (Invitrogen, Life Technologies, Carlsbad, CA, USA) was used following the manufacturer's protocol. pPH cells were harvested, washed in PBS, and stained with Annexin V-FITC and propidium iodide. The cells were incubated at room temperature for $15 \mathrm{~min}$ and fluorescence was measured by flow cytometry (BD LSR II Flow Cytometer, BD Biosciences, San Jose, CA, USA). The data was analyzed using FCS Express 4 software. One-way analysis of variance (ANOVA) followed by Dunnett post-test was performed to determine significant difference among treatments.

\section{AFP secretion}

Cell lines were cultured for 48 hours in $5 \mathrm{ml}$ of medium and AFP levels for $1 \times 10^{6}$ plated cells were determined using a porcine AFP ELISA kit (MyBioSource, Inc, San Diego, CA, USA).

\section{Xenograft tumorigenesis assays}

pHCC cell lines (passage 9) were evaluated for tumorigenicity by injecting $2.5 \times 10^{6}$ cells (in $100 \mu$ of Matrigel, BD Biosciences, San Diego, CA, USA) SC into 6 SCID (NOD.CB17-Prkdcscid/ JAX, Bar Harbor, ME, USA) female mice (2 sites/cell line). Tumor growth data was subjected to multiple linear regression analysis using StatPlus software. Following verification of pHCC tumorigenicity by day 21 post injection (monitoring by palpation), cells $\left(1 \times 10^{6}\right.$ cells in $25 \mu$ l Matrigel) were injected into the liver parenchyma of 9 SCID female mice (3 sites/cell line). After 21 days, animals were euthanized and evaluated for tumor growth.

\section{Autologous tumorigenesis assay}

An additional pHCC cell line was established using a surgically resected liver from a single Oncopig (112 days of age) and transformed as described above. At 81 days post resection pHCC cells (passage 9) were harvested, washed 3 times with serum free media, diluted to a total volume of $1 \mathrm{ml} \mathrm{DMEM}$, and autologously injected into 3
$\mathrm{SC}$ sites $\left(1.0 \times 10^{7}, 1.25 \times 10^{6}\right.$ or $7.8 \times 10^{4}$ per site). Injection sites were monitored visually, by palpation, and by biopsy. On day 46 post injection the animal was euthanized and tissues collected for further analysis.

\section{Immunocytochemistry}

Cytological and histomorphological features of cell lines and tumors were evaluated by H\&E, Hep Par-1 (Leica Biosystems, Wetzlar, Germany), vimentin (Biocare Medical, Concord, CA, USA), cytokeratin (Biocare Medical, Concord, CA, USA), and CD3 (Santa Cruz Biotech, Santa Cruz, CA, USA) staining as previously described [4]. Staining was performed at passage 9 for pHCC cells and culture day 2 for $\mathrm{pPH}$ cells.

\section{Transgene expression}

$K R A S^{\mathrm{G} 12 \mathrm{D}}$ and $T P 53^{\mathrm{R} 167 \mathrm{H}}$ transgene expression was determined using RT-PCR as previously described [4]. RNA from previously isolated Oncopig primary fibroblasts [4] were used as a negative control.

\section{Transcriptomic analysis}

RNA-seq was performed on Oncopig cell lines as previously described [4], adjusting the -mate-innerdist option to 50 and the - mate-std-dev option to 450 in the alignment step, and utilizing cuffdiff for differential analysis. An average of 29 million raw stranded pairedend reads were produced for each cell line (Supplementary Table 7). The datasets are available in the European Nucleotide Archive under accession number PRJEB8646, samples ERS1210942-ERS1210947 (www.ebi.ac.uk/ena/ data/view/PRJEB8646). Genes orthologous to human genes with $\log 2$ fold change $\geq 1$ or $\leq-1$ and a $q$ value $\leq 0.05$ were considered differentially expressed. Gene transcription levels are represented as fragments per kilobase of transcript per million mapped reads (FPKM). GO term and pathway enrichment analysis for DEGs was performed as previously described [5], using all genes as a background.

\section{qPCR}

Expression of important drug metabolism enzymes, regulatory genes, and hepatocyte functional genes were determined in $\mathrm{pPH}$ (day $0,1,3,5,8$, and 15 of culture) and pHCC cells cultured in DMSO (passage 8) using qPCR. In addition, RNA-seq results were validated by qPCR using randomly chosen genes displaying elevated and reduced expression in the RNA-seq datasets. qPCR was performed using the Power SYBR green PCR Master Mix (Applied Biosystems, Foster City, CA, USA) as previously described [4]. The thermal cycling conditions were one cycle of $50^{\circ} \mathrm{C}$ for $2 \mathrm{~min}$ and $95^{\circ} \mathrm{C}$ for $10 \mathrm{~min}$, followed by 40 cycles of $95^{\circ} \mathrm{C}$ for $15 \mathrm{sec}$ and $60^{\circ} \mathrm{C}$ for $1 \mathrm{~min}$. Fold 
changes were determined using the $2^{-\Delta \Delta \mathrm{Ct}}$ method by normalizing to $G A P D H$ and $A C T B$. Primers are provided in Supplementary Table 6.

\section{Identification of master regulators}

Master regulators of gene expression were identified in Oncopig and 18 human HCC cell lines [49] using the cytoscape plugin iRegulon v1.3 [50]. iRegulon utilizes expression data to uncover regulatory relationships through reverse-engineering of gene regulatory networks, allowing for the identification of TFs underlying altered expression of co-expressed genes. Specifically, iRegulon utilizes a list of co-expressed genes and cis-regulatory sequence information from multiple species to identify TFs underlying genome-wide expression changes. Relative expression levels for human HCC cell lines were extracted from http://medicalgenomics.org/cellminerhcc, and genes with a $\log 2$ fold change $>1$ or $<-1$ relative to controls were considered differentially expressed. DEGs displaying elevated and reduced expression were analyzed separately for each cell line to identify master regulators of genomewide increases and decreases in expression, respectively. TF binding motifs with a normalized enrichment score $>3$ were considered significantly enriched, which corresponds to a false discovery rate (q-value) between 3\% and 9\% [50].

\section{Cirrhosis induction}

Liver cirrhosis was induced in 2 Oncopigs as previously described [51]. Procedures were undertaken following induction of general anesthesia. Briefly, with the Oncopig in a supine position, the groin area was sterilely prepped and draped. Femoral arterial access was gained via ultrasound guided vascular access, with placement of a 5 French vascular sheath (Pinnacle; Terumo, Somerset, NJ, USA). Using standard catheter and wire techniques, celiac arteriography was performed using a 5 French catheter (GLIDECATH; Terumo, Somerset, NJ, USA). A coaxial 3 French microcatheter (Renegade Hi-flo; Boston Scientific, Natick, MA, USA) was then advanced into the proper hepatic artery, and an emulsion of absolute ethanol and ethiodized oil (Lipiodol; Guerbet, Villepinte, France) (1:3 v/v dosed at $0.75 \mathrm{~mL} / \mathrm{kg}$ ) was slowly infused by manual injection into the hepatic arterial circulation over approximately 45-60 minutes. All devices were then removed, and hemostasis was obtained by direct compression at the vascular access site. Assessments were performed by a human pathologist according to the METAVIR system [52].

\section{Abbreviations}

AdCre - adenovirus encoding Cre

AFP - alpha-fetoprotein

DEGs - differentially expressed genes

FPKM - fragments per kilobase of transcript per million mapped reads
GO - gene ontology
HCC - hepatocellular carcinoma
LRTs - locoregional therapies
$\mathrm{NASH}$ - nonalcoholic steatohepatitis
OCM - Oncopig cancer model
PBS - phosphate buffer saline
pHCC - porcine HCC
$\mathrm{pPH}$ - porcine primary hepatocytes
$\mathrm{SC}$ - subcutaneous
SCID - severe combined immunodeficiency
TFs - transcription factors

\section{Author contributions}

Conception and design: LBS

Development of methodology LAR, AD

Acquisition of data: KMS, LAR, AD, KADO, DRP

Analysis and interpretation of data: KADO, KMS, $\mathrm{KS}, \mathrm{GG}$

Writing, review and/or revision of the manuscript:

LBS, KMS, RG, CER, HO, RS, KADO, LAR, DRP, GG

Administrative, technical, or material support: RS

Study supervision: LBS

\section{ACKNOWLEDGMENTS}

The authors also wish to express their gratitude to Dr Laura Selmic (UIUC Department of Veterinary Clinical Medicine) for performing the liver resections, and Dr Patrick Roady (UIUC Veterinary Diagnostic Lab) for reviewing histopathology.

\section{CONFLICTS OF INTEREST}

The authors declare no conflict of interest.

\section{FUNDING}

This research was supported by grants from the USDA/ARS (AG 58-5438-2-3070), the NIH (RFAGM-09-008), the DOD (CA150590), and by grants from the Cooperative Research Program for Agriculture Science \& Technology Development (PJ009103) of the Rural Development Administration, Republic of Korea.

\section{REFERENCES}

1. El-Serag HB, Marrero JA, Rudolph L, Reddy KR. Diagnosis and treatment of hepatocellular carcinoma. Gastroenterology. 2008; 134: 1752-63.

2. Llovet JM, Ricci S, Mazzaferro V, Hilgard P, Gane E, Blanc JF, de Oliveira AC, Santoro A, Raoul JL, Forner A, Schwartz M, Porta C, Zeuzem S, et al. Sorafenib in advanced hepatocellular carcinoma. N Engl J Med. 2008; 359: 378-90. 
3. Hyder O, Dodson RM, Nathan H, Herman JM, Cosgrove D, Kamel I, Geschwind JF, Pawlik TM. Referral patterns and treatment choices for patients with hepatocellular carcinoma: a United States population-based study. J Am Coll Surg. 2013; 217: 896-906.

4. Schook LB, Collares TV, Hu W, Liang Y, Rodrigues FM, Rund LA, Schachtschneider KM, Seixas FK, Singh K, Wells KD, Walters EM, Prather RS, Counter CM. A genetic porcine model of cancer. PLoS One. 2015; 10: e0128864.

5. Schachtschneider KM, Madsen O, Park C, Rund LA, Groenen MA, Schook LB. Adult porcine genome-wide DNA methylation patterns support pigs as a biomedical model. BMC Genomics. 2015; 16: 743.

6. Adam SJ, Rund LA, Kuzmuk KN, Zachary JF, Schook LB, Counter CM. Genetic induction of tumorigenesis in swine. Oncogene. 2007; 26: 1038-45.

7. Schoenleber SJ, Kurtz DM, Talwalkar JA, Roberts LR, Gores GJ. Prognostic role of vascular endothelial growth factor in hepatocellular carcinoma: systematic review and meta-analysis. Br J Cancer. 2009; 100: 1385-92.

8. Pleguezuelo M, Marelli L, Misseri M, Germani G, Calvaruso V, Xiruochakis E, Manousou P, Burroughs AK. TACE versus TAE as therapy for hepatocellular carcinoma. Expert Rev Anticancer Ther. 2008; 8: 1623-41.

9. Canzonieri V, Alessandrini L, Caggiari L, Perin T, Berretta M, Cannizzaro R, De Re V. Hepatocellular carcinoma: an overview of clinico-pathological and molecular perspectives. World Cancer Res J. 2015; 2: e485.

10. Llovet JM, Bruix J. Molecular targeted therapies in hepatocellular carcinoma. Hepatology. 2008; 48: 1312-27.

11. Aninat C, Piton A, Glaise D, Le Charpentier T, Langouët S, Morel F, Guguen-Guillouzo C, Guillouzo A. Expression of cytochromes P450, conjugating enzymes and nuclear receptors in human hepatoma HepaRG cells. Drug Metab Dispos. 2005; 34: 75-83.

12. Paradis V. Histopathology of hepatocellular carcinoma. In: Vauthey JN, Brouquet A, editors. Multidisciplinary Treatment of Hepatocellular Carcinoma, Recent Results in Cancer Research. Springer-Verlag; 2013. p. 21-32.

13. Benzekry S, Lamont C, Beheshti A, Tracz A, Ebos JM, Hlatky L, Hahnfeldt P. Classical mathematical models for description and prediction of experimental tumor growth. PLoS Comput Biol. 2014; 10: e1003800.

14. Wei T, Zhang LN, Lv Y, Ma XY, Zhi L, Liu C, Ma F, Zhang $\mathrm{XF}$. Overexpression of platelet-derived growth factor receptor alpha promotes tumor progression and indicates poor prognosis in hepatocellular carcinoma. Oncotarget. 2014; 5: 10307-17. doi: 10.18632/oncotarget.2537.

15. Moon WS, Rhyu KH, Kang MJ, Lee DG, Yu HC, Yeum JH, Koh GY, Tarnawski AS. Overexpression of VEGF and angiopoietin 2: a key to high vascularity of hepatocellular carcinoma? Mod Pathol. 2003; 16: 552-7.
16. Huang H, Bhat A, Woodnutt G, Lappe R. Targeting the ANGPT-TIE2 pathway in malignancy. Nat Rev Cancer. 2010; 10: 575-85.

17. Raica M, Cimpean AM. Platelet-derived growth factor (PDGF)/PDGF receptors (PDGFR) axis as target for antitumor and antiangiogenic therapy. Pharmaceuticals. 2010; 3: 572-99.

18. Laschke MW, Elitzsch A, Vollmar B, Vajkoczy P, Menger MD. Combined inhibition of vascular endothelial growth factor (VEGF), fibroblast growth factor and plateletderived growth factor, but not inhibition of VEGF alone, effectively suppresses angiogenesis and vessel maturation in endometriotic lesions. Hum Reprod. 2006; 21: 262-8.

19. Maestro R, Dei Tos AP, Hamamori Y, Krasnokutsky S, Sartorelli V, Kedes L, Doglioni C, Beach DH, Hannon GJ. Twist is a potential oncogene that inhibits apoptosis. Genes Dev. 1999; 13: 2207-17.

20. Lee TK, Poon RT, Yuen AP, Ling MT, Kwok WK, Wang XH, Wong YC, Guan XY, Man K, Chau KL, Fan ST. Twist overexpression correlates with hepatocellular carcinoma metastasis through induction of epithelial-mesenchymal transition. Clin Cancer Res. 2006; 12: 5369-76.

21. Walczak H. Death receptor-ligand systems in cancer, cell death, and inflammation. Cold Spring Harb Perspect Biol. 2013; 5: a008698.

22. Ossina NK, Cannas A, Powers VC, Fitzpatrick PA, Knight JD, Gilbert JR, Shekhtman EM, Tomei LD, Umansky SR, Kiefer MC. Interferon-gamma modulates a p53-independent apoptotic pathway and apoptosis-related gene expression. J Biol Chem. 1997; 272: 16351-7.

23. Wei Y, Jiang J, Sun M, Chen X, Wang H, Gu J. ATF5 increases cisplatin-induced apoptosis through up-regulation of cyclin D3 transcription in HeLa cells. Biochem Biophys Res Commun. 2006; 339: 591-6.

24. Minguez B, Tovar V, Chiang D, Villanueva A, Llovet JM. Pathogenesis of hepatocellular carcinoma and molecular therapies. Curr Opin Gastroenterol. 2009; 25: 186-94.

25. Totoki Y, Tatsuno K, Covington KR, Ueda H, Creighton CJ, Kato M, Tsuji S, Donehower LA, Slagle BL, Nakamura H, Yamamoto S, Shinbrot E, Hama N, et al. Trans-ancestry mutational landscape of hepatocellular carcinoma genomes. Nat Genet. 2014; 46: 1267-73.

26. Pez F, Lopez A, Kim M, Wands JR, Caron de Fromentel C, Merle P. Wnt signaling and hepatocarcinogenesis: molecular targets for the development of innovative anticancer drugs. J Hepatol. 2013; 59: 1107-17.

27. Suzuki T, Yano H, Nakashima Y, Nakashima O, Kojiro M. Beta-catenin expression in hepatocellular carcinoma: a possible participation of beta-catenin in the dedifferentiation process. J Gastroenterol Hepatol. 2002; 17: 994-1000.

28. Giakoustidis A, Giakoustidis D, Mudan S, Sklavos A, Williams R. Molecular signalling in hepatocellular carcinoma: role of and crosstalk among WNT/ $\beta$-catenin, 
Sonic Hedgehog, Notch and Dickkopf-1. Can J Gastroenterol Hepatol. 2015; 29: 209-17.

29. Tung EK, Wong BY, Yau TO, Ng IO. Upregulation of the Wnt co-receptor LRP6 promotes hepatocarcinogenesis and enhances cell invasion. PLoS One. 2012; 7: e36565.

30. Bengochea A, de Souza MM, Lefrançois L, Le Roux E, Galy O, Chemin I, Kim M, Wands JR, Trepo C, Hainaut P, Scoazec JY, Vitvitski L, Merle P. Common dysregulation of Wnt/Frizzled receptor elements in human hepatocellular carcinoma. Br J Cancer. 2008; 99: 143-50.

31. Lachenmayer A, Alsinet C, Savic R, Cabellos L, Toffanin S, Hoshida Y, Villanueva A, Minguez B, Newell P, Tsai HW, Barretina J, Thung S, Ward SC, et al. Wnt-pathway activation in two molecular classes of hepatocellular carcinoma and experimental modulation by sorafenib. Clin Cancer Res. 2012; 18: 4997-5007.

32. Kuzmuk KN, Schook LB. Pig as a model for biomedical sciences. In: Rothschild MF, Ruvinsky A, editors. The Genetics of the Pig. Vol. Sec 2. CAB international; 2011. p. 426-444.

33. Schook LB, Kuzmuk K, Adam S, Rund L, Chen K, Rogatcheva M, Mazur M, Pollock C, Counter C. DNAbased animal models of human disease: from genotype to phenotype. Dev Biol. 2008; 132: 15-25.

34. Tissot RG, Beattie CW, Amoss MS Jr. Inheritance of Sinclair swine cutaneous malignant melanoma. Cancer Res. 1987; 47: 5542-5.

35. Swindle MM. Swine in the Laboratory: Surgery, Anesthesia, Imaging, and Experimental Techniques, Second Edition. CRC Press; 2007.

36. Swindle MM. Swine as Models in Biomedical Research, First Edition. Iowa State University Press; 1992.

37. Swindle MM, Makin A, Herron AJ, Clubb FJ, Frazier KS. Swine as models in biomedical research and toxicology testing. Vet Pathol. 2012; 49: 344-56.

38. Hui KM. Human hepatocellular carcinoma: expression profiles-based molecular interpretations and clinical applications. Cancer Lett. 2009; 286: 96-102.

39. Li X, Zhou X, Guan Y, Wang YX, Scutt D, Gong QY. $\mathrm{N}$-nitrosodiethylamine-induced pig liver hepatocellular carcinoma model: radiological and histopathological studies. Cardiovasc Intervent Radiol. 2006; 29: 420-8.

40. Mitchell J, Tinkey PT, Avritscher R, Van Pelt C, Eskandari G, Konnath George S, Xiao L, Cressman E, Morris JS, Rashid A, Kaseb AO, Amin HM, Uthamanthil R. Validation of a preclinical model of diethylnitrosamine-induced hepatic neoplasia in Yucatan miniature pigs. Oncology. 2016; 91: 90-100.

41. Tangkijvanich $P$, Anukulkarnkusol N, Suwangool $\mathrm{P}$, Lertmaharit S, Hanvivatvong O, Kullavanijaya $\mathrm{P}$, Poovorawan Y. Clinical characteristics and prognosis of hepatocellular carcinoma: analysis based on serum alphafetoprotein levels. J Clin Gastroenterol. 2000; 31: 302-8.
42. Rygaard K, Spang-Thomsen M. Quantitation and Gompertzian analysis of tumor growth. Breast Cancer Res Treat. 1997; 46: 303-12.

43. Sun HC, Tang ZY. Angiogenesis in hepatocellular carcinoma: the retrospectives and perspectives. J Cancer Res Clin Oncol. 2004; 130: 307-19.

44. Noh JH, Jung KH, Kim JK, Eun JW, Bae HJ, Xie HJ, Chang YG, Kim MG, Park WS, Lee JY, Nam SW. Aberrant regulation of HDAC2 mediates proliferation of hepatocellular carcinoma cells by deregulating expression of G1/S cell cycle proteins. PLoS One. 2011; 6: e28103.

45. Lazarevich NL, Shavochkina DA, Fleishman DI, Kustova IF, Morozova OV, Chuchuev ES, Patyutko YI. Deregulation of hepatocyte nuclear factor 4 (HNF4)as a marker of epithelial tumors progression. Exp Oncol. 2010; 32: 167-71.

46. Wang J, Zhu CP, Hu PF, Qian H, Ning BF, Zhang Q, Chen F, Liu J, Shi B, Zhang X, Xie WF. FOXA2 suppresses the metastasis of hepatocellular carcinoma partially through matrix metalloproteinase-9 inhibition. Carcinogenesis. 2014; 35: 2576-83.

47. Li M, Luo RZ, Chen JW, Cao Y, Lu JB, He JH, Wu QL, Cai MY. High expression of transcriptional coactivator p300 correlates with aggressive features and poor prognosis of hepatocellular carcinoma. J Transl Med. 2011; 9: 5.

48. Meng FY, Chen ZS, Han M, Hu XP, He XX, Liu Y, He WT, Huang W, Guo H, Zhou P. Porcine hepatocyte isolation and reversible immortalization mediated by retroviral transfer and site-specific recombination. World J Gastroenterol. 2010; 16: 1660-4.

49. Staib F, Krupp M, Maass T, Itzel T, Weinmann A, Lee JS, Schmidt B, Müller M, Thorgeirsson SS, Galle PR, Teufel A. CellMinerHCC: a microarray-based expression database for hepatocellular carcinoma cell lines. Liver Int. 2014; 34 : 621-31.

50. Janky R, Verfaillie A, Imrichová H, Van de Sande B, Standaert L, Christiaens V, Hulselmans G, Herten K, Naval Sanchez M, Potier D, Svetlichnyy D, Kalender Atak Z, Fiers M, et al. iRegulon: from a gene list to a gene regulatory network using large motif and track collections. PLoS Comput Biol. 2014; 10: e1003731.

51. Avritscher R, Wright KC, Javadi S, Uthamanthil R, Gupta S, Gagea M, Bassett RL, Murthy R, Wallace MJ, Madoff DC. Development of a large animal model of cirrhosis and portal hypertension using hepatic transarterial embolization: a study in swine. J Vasc Interv Radiol. 2011; 22: 1329-34.

52. Bedossa P, Poynard T. An algorithm for the grading of activity in chronic hepatitis $\mathrm{C}$. The METAVIR Cooperative Study Group. Hepatology. 1996; 24: 289-93. 